\title{
Ideologías e identidades en el Léxico Judío Latinoamericano ${ }^{1}$
}

\author{
Charlotte Gartenberg* \\ The City University of New York, Graduate Center
}

\begin{abstract}
Resumen
Creado en 2013, el Léxico Judio Latinoamericano, "una base de datos colaborativa de palabras que usan los judíos hispanohablantes de Latinoamérica y el Caribe, en la escritura y en el habla" (http:// www.jewish-languages.org/lexico-judio-latinoamericano/welcome), propone, a propósito o no, la existencia de un grupo coherente de judíos latinoamericanos. Basándose en las ideas de Benedict Anderson y Joshua Fishman sobre el rol del lenguaje en los proyectos nacionalistas, se puede decir que un diccionario desempeña un papel especial en la creación de identidades grupales. En cierto sentido, un diccionario valida, oficializa e institucionaliza la lengua de sus hablantes, en cierta manera representando y prescribiendo los usos del lenguaje y los hábitos de comportamiento de sus locutores. El $L J L$ no solo incluye vocablos de distintas regiones latinoamericanas y diferentes grupos judíos sino también se arma de manera atípica: es un proyecto en desarrollo constante donde los usuarios presentan las entradas para ser incluidas. En este artículo, nos interesa examinar las consecuencias ideológicas de la composición y de la constitución del
\end{abstract}

\footnotetext{
Quiero agradecer a José del Valle su ayuda indispensable en la escritura y edición de este artículo.

* Para correspondencia, dirigirse a: Charlotte Gartenberg (Charlotte.Gartenberg@gmail. com), The City University of New York, Graduate Center (818) 481-4596.
} 
Léxico. Preguntaremos ¿qué perspectiva facilita plantear un pueblo judío latinoamericano y cómo influyen las identidades de los que encabezan el proyecto en las posibilidades simbólicas del Léxico? ¿Cuáles son los efectos de formar un artefacto de identidad grupal de forma supuestamente colaborativa? Finalmente, ¿qué pretende ser y qué funciones quiere cumplir el Léxico Judío Latinoamericano?

Palabras clave: judíos, léxico, ideologías lingüísticas, identidad grupal.

IDEOLOGIES AND IDENTITIES IN THE LÉXICO JUDÍO LATINOAMERICANO

Abstract

Created in 2013, the Léxico Judio Latinoamericano, "a collaborative data base of words used by Spanish-speaking Jews from Latin America and the Caribbean, in writing and in speaking" (http:// www.jewish-languages.org/lexico-judio-latinoamericano/welcome), proposes, purposefully or not, the existence of a coherent group of Latin American Jews. Based on the ideas of Benedict Anderson and Joshua Fishman about the role of language in national projects, one can say that a dictionary plays a special role in the creation of group identities. In a certain sense, a dictionary validates, institutionalizes and makes official that language of its users, in some way representing and prescribing the uses of the language and the behavioral habits of its speakers. The $L J L$ not only includes vocabulary from distinct Latin American regions and different groups of Jews but also is put together in an atypical way: it is a project in constant development where the users present entries to be included. In this article, we are interested in examining the ideological consequences of the composition and constitution of the $L J L$. We will ask, what perspectives facilitate positing a Latin American Jewish people and how do the identities of those who head the project influence the symbolic possibilities of the Lexico? What are the effects of forming an artifact of group identity in supposedly collaborative way? Finally, what does the Léxico Judio Latinoamericano hope to be and what functions does it aim to accomplish?

Keywords: Jews, lexicons, linguistic ideologies, group identity.

Recibido: 08/01/2016 Aceptado: 18/10/2016 


\section{INTRODUCCIÓN}

El acto de crear un diccionario -ya sea monolingüe, bilingüe, especializado o destinado al uso cotidiano- no es una acción neutra. Las decisiones con respecto al contenido, la estructura, el proceso de selección y los comentarios introductorios al volumen sugieren ciertas metas y/o actitudes de los autores, de su entorno y de la sociedad cuya lengua se intenta representar. Tanto los elementos paratextuales (Lauria 2010a) como los artículos lexicográficos (Rodríguez Barcia 2008) contienen cargas ideológicas que comunican. Un diccionario se puede dirigir a, tratar sobre y estar hecho por un colectivo humano cuyo idioma documenta. Establece y explica normas para los hablantes nativos y no nativos. Contiene el poder de la neutralidad documentada, de la observación científica, pero no puede evitar impartir sesgos y mensajes extralingüísticos ${ }^{2}$. Como dice Luis Fernando Lara de los diccionarios monolingües, son concebidos "como catálogos verdaderos de la lengua de la comunidad lingüística, no como obras de autores particulares, sujetas a gustos, modas y biografías, sino como lengua en sí, como la lengua de la sociedad en su conjunto" (1996: 16).

Esta misma dimensión ideológica se encuentra en cualquier léxico, y presenta un perfil particular cuando se trata de un diccionario especializado que, escrito en un idioma mayoritario como el español, pretende reunir las características léxicas de un grupo minoritario como el judío. Es por eso que cuando reflexionamos sobre el nuevo Léxico Judio Latinoamericano -un proyecto inaugurado recién en el año 2013- hay que pensar en lo que comunica no solo mediante las definiciones de las palabras que reúne sino más allá de las mismas. Iniciado por una antropóloga estadounidense, Evelyn Dean-Olmsted, y con el apoyo de las organizaciones que dirigen su homólogo en inglés, el Jewish English Lexicon, el sitio web busca reunir y documentar los judaísmos léxicos de los hispanohablantes latinoamericanos, esto es, las palabras judías que usan los judíos latinoamericanos de ascendencia askenazí, sefardí y árabe, procedentes de fuentes y lenguas diversas desde el hebreo bíblico al español moderno. Su página de bienvenida explica:

2 De la tradición crítica que ha estudiado la dimensión ideológica de los diccionarios destacamos Lara 1996, Forgas 1996, 2001, Benson 2001, Seargeant 2011, Lauria 2010a y Rodríguez Barcia 2008. 
Bienvenidos al Léxico Judío Latinoamericano, una base de datos colaborativa de palabras que usan los judíos hispanohablantes de Latinoamérica y el Caribe, en la escritura y en el habla.

Las palabras incluidas en esta base de datos se derivan de muchos idiomas hablados por los judíos desde el pasado hasta la época actual. Entre ellos se encuentran el hebreo y el arameo de los textos bíblicos y rabínicos; el judeo-árabe, ladino e ídish de las antiguas tierras ancestrales y el hebreo moderno del Estado de Israel. Asimismo, la base de datos incluye palabras y frases en español que tienen significados únicos entre judíos y cuyo sentido varía cuando se usan entre hablantes judíos o entre hablantes no judíos (http://www.jewish-languages.org/lexico-judio-latinoamericano/ welcome).

Por el momento, solo contiene ciento cincuenta y tres lemas, pero aspira a recoger muchos más mediante la ayuda de sus usuarios. Este proyecto nos permite plantearnos preguntas sobre las opiniones y ambiciones -conscientes o no- de sus gestores. En lo que sigue, examinamos las posibles bases ideológicas del léxico: las decisiones editoriales, la combinación de palabras procedentes de distintos idiomas, ámbitos y registros, el proceso abierto de selección y los medios por los cuales se transmite.

\section{IDEOLOGÍAS LINGÜÍSTICAS Y LENGUA}

Al referirnos arriba a las bases "ideológicas" del léxico que es objeto de nuestro análisis, nos situamos en un campo organizado en torno a las ideologías lingüísticas. Éstas han sido definidas por Kathryn Woolard como "[r]epresentations, whether explicit or implicit, that construe the intersection of language and human beings in a social world" (Woolard 1998: 3). Pretendemos, por tanto, entender la relación entre un determinado modelo de representación del lenguaje (de una lengua, un dialecto, un acento o un conjunto de palabras) y el contexto social de su producción y recepción. Nos interesa, en particular, el modo en que estas representaciones ideológicas del lenguaje están ancladas en los intereses de algún colectivo y la medida en que contribuyen a naturalizarlo (Del Valle 2007).

En su análisis de las ideologías lingüísticas, Paul Kroskrity considera esencial mencionar que, "[1]anguage, especially shared language, has long served as the key to naturalizing the boundaries of social groups" (1999: 23). Por lo general, eso se ha interpretado en los últimos siglos en términos 
nacionales. John Myhill, basándose en Benedict Anderson y Joshua Fishman (los dos citados en Myhill 2006), explica que:

It is commonly recognized that linguistic ideology has played a central role in nationalist movements and that national identities have been constructed around the idea that members of the national group share a common language (2006: 2).

El uso intencional del idioma como rasgo unificador de naciones ha sido observable desde la época del crecimiento del nacionalismo moderno y con las primeras creaciones de los Estados-nación. Uno de sus proponentes más citados fue Johann Gottlieb Fichte, quien en su discurso a "la nación alemana" en 1806 -cuando Alemania todavía no estaba unificada-atribuyó fronteras internas, originales y naturales a los Estados. Un pueblo-Estado está unido primordialmente por el entendimiento mutuo; es "sufficiently united within itself by a common language and a common way of thinking, and sharply enough severed from the other peoples" (citado en Joseph 2004:110). Aquí vemos un modelo de pensamiento que rige los proyectos nacionales al emplear el idioma a su favor identificando la lengua con una manera de percibir el mundo que contrasta con respecto a la de otros pueblos. Estas apreciaciones dependen de un punto de vista que considera la lengua como proceso social. Susan Gal y Judith Irvine notan que éste procede de formas anticuadas de evaluar los idiomas. Entre los investigadores del siglo XIX era común considerar los idiomas como marca incuestionable de diferencia porque " $[t]$ o them, languages were natural objects, consequences of spiritual or even biological differences between populations" y vinculan esta inclinación a proyectos y conceptos nacionalistas: "[a] corollary was that identifying languages was the same as identifying nations" (Gal e Irvine 1995: 968). Se lamentan del hecho de que estas nociones del XIX sigan siendo fundamento de muchos estudios contemporáneos y alertan en contra del "commonplace in sociolinguistics that linguistic forms, including whole languages, can be indexes of social groups", porque a partir de esta idea crean "linguistic ideologies that purport to explain the source and meaning of the linguistic differences" que caracterizan grupos enteros (973). Esta tendencia, que Gal e Irvine llaman "iconicity", puede llegar a exceder los límites de los estudios lingüísticos porque aún "with in the social sciences, the persistent use of language as a synecdoche for community relies unquestioningly on the supposedly natural correlation of one language with one culture" (3-4). A pesar de ser un modo de pensar obsoleto, que toma el lenguaje como objeto restringido plenamente documentable y explicable, estos conceptos persisten 
hasta hoy y aunque se puede reconocer su naturaleza mítica ${ }^{3}$, siguen siendo parte integral de los proyectos nacionalistas.

\section{LA IDENTIDAD JUDÍA Y LAS LENGUAS}

Esta asociación implícita entre el idioma y la nación como base de la constitución de un sentimiento de solidaridad entre miembros de un grupo ha sido y, a la vez, no ha sido el caso para la llamada "nación judía" en el período moderno. Primero, en la historia de los judíos solo ha habido dos idiomas de los cuales se pueda decir que todos o casi todos los judíos tuvieran cierto dominio en los tiempos antiguos, antes del siglo XI AC, a saber, el hebreo y el arameo. Con la diáspora, los judíos se dispersaron por el mundo y aprendieron los idiomas de sus nuevas regiones y, en la mayoría de los casos, desarrollaron sus propias variedades como resultado del contacto entre las lenguas que hablaban y las que adquirían. De ahí provienen (a veces denominadas judeolenguas) el judeoárabe -árabe escrito en letras hebreas con palabras hebreas y arameas-, el ladino o judeoespañol, también escrito en letras hebreas con palabras hebreas y arameas ${ }^{4}$, y el ídish -idioma germánico escrito en letras hebreas con rasgos eslavos y palabras hebreas y arameas $^{5}$. Myhill describe el vínculo entre lengua y nación para los judíos europeos durante el siglo XIX de la siguiente manera:

In the course of the 19th century, language-based nationalism exerted an enormous influence on European Jews. There were a variety of ways in which Jews could apply this ideology to their own situation, particularly because the language which all Jews shared as part of their identity, Hebrew, was no longer spoken; in this respect, Jews resembled the other

3 Joseph explica “que [t]he 'nation-state myth'-that basic view of the world as consisting naturally of nation-states- is bound up with an assumption that national languages are a primordial reality" (2004: 98).

4 Hay diferentes variedades del ladino que demuestran la influencia de los distintos lugares en que se desarollaron. Unas variedades incluyen palabras judeo-árabes o elementos turcos, griegos, franceses, italianos, o incluso de las lenguas balcánicas.

5 Para reflexiones y más información sobre la historia y definiciones de "judeolenguas", vea la introducción de Myhill (2004) y Spolsky (2014) capítulos 7 (sobre el árabe), 9 (sobre el ladino) y 12 (sobre el ídish). 
national church groups who had partially or entirely ceased to speak their national languages (2006: 101).

Debido a esta situación, los judíos hubiesen podido pensarse parte de los Estados-nación donde vivían por el hecho de compartir un idioma. Pero, para la mayoría de los judíos esto no era posible, no solo porque sus compatriotas gentiles $^{6}$ no los consideraban como paisanos/compatriotas sino también porque no podían dejar de considerarse étnicamente como judíos. Myhill clarifica a este respecto:

For the overwhelming majority of Jews, however, this was not a realistic option; they identified themselves as ethnic Jews, and they could not commit themselves to an alternative national identity based upon their spoken language the way that, e.g. German Christians could (101).

Otra opción fue invertir en un sentimiento nacional judío a través del lenguaje, elevando un idioma judío a un nivel más oficial, estandarizándolo e invirtiendo en la distribución de la cultura secular en ese idioma. Aunque lo hicieron y se vieron muchos intentos de utilizar el ídish, el judeoárabe y el ladino para fomentar un sentimiento de solidaridad nacional (Myhill 2006: 102), la dispersión geográfica y la existencia de múltiples idiomas judíos impidieron que la lengua se convirtiera en la base de la unificación nacional del pueblo judío. Esta idea gentil sirvió para impulsar la recuperación del hebreo en el Estado de Israel, pero aún hoy, el hecho de hablar hebreo no representa la identidad judía para todos los judíos.

Esto no significa que la lengua materna no sirviera como eje unificador para los judíos de ninguna manera. El ladino, el ídish y el judeo-árabe han servido para nombrar e identificar miembros de los grupos sefardí, askenazí y árabe, respectivamente, y para establecer vínculos inmediatos con gente desconocida. Rafael Patai afirma que durante el siglo XVII un judío asquenazí

could start out from Moscow, and in every city on the way all across the continent as far west as London he could talk to the Jews in his own mother tongue which was also theirs, could transact business with them, settle among them, and easily feel at home with them (citado en Myhill 2004: 127).

6 La palabra "gentil" se refiere a personas no judías. 
Así, el ídish podía establecer una alianza entre gente de lugares distintos y lejanos, y simbolizaba experiencias vitales similares. Si bien esta condición persiste en la época moderna, aunque ya no en esas dimensiones tan amplias, sigue sirviendo como marcador identitario por su implicación de experiencias, historias y puntos de vista similares. El ladino también sigue funcionando como símbolo unificador para sus hablantes. Según Angelina Muñiz Huberman, la preservación del judeoespañol por los judíos sefardíes exiliados sirve como prueba de que el idioma puede exhibir identidad y desempeñar un rol en el reconocimiento y establecimiento de un hogar judío en todas partes del mundo (2005: 16). En México, se nombra a diferentes pueblos judíos por el idioma con el que se asocian. Así se suele usar "ídish" o "los de la colonia ídish" para referirse a los que provienen de la Europa del Este en lugar de llamarlos askenazíes. El libro semi-autobiográfico Novia que te vea, de Rosa Nissán, que cuenta la juventud de una hija de inmigrantes judíos sefardíes procedentes de Turquía en la Ciudad de México de los años 1950, representa un buen ejemplo del uso de esta práctica para reforzar diferencias entre los distintos pueblos judíos del país. La protagonista explica a su amiga por qué no pasa tiempo con las chicas askenazíes:

Las turcas nos sentíamos las dueñas de la escuela; íbamos al mismo templo, y éramos amigas porque nuestras mamás hablan en ladino y piensan igualito: nos dan los mismos permisos y no permisos. Estas cuatas son ídish y se creen mucho (1992: 100).

Vemos cómo aquí la identificación de uno mismo y de los otros pasa a través del idioma e implica un cierto habitus y manera de pensar. La protagonista justifica su desdén por el otro grupo de judíos refiriéndose a su identidad lingüística. Este ejemplo también nos indica algo esencial de las capacidades unificadoras de las lenguas judías; no obstante, la camaradería que promueven se limita a sus propios hablantes y no se extiende a todos los judíos. Antes de llegar a América, la geografía separaba a esos distintos grupos judíos y los idiomas encarnaban prototípicamente la fractura del pueblo judío producida por el exilio. En distintas partes del mundo, los grupos judíos desarrollaron sus propios idiomas y lenguas rituales. Sin embargo, hoy en día, cuando la inmigración en las Américas ha superado el obstáculo del espacio, sus miembros preservan las divisiones no solo a través de lenguas y prácticas divergentes sino además manteniendo sus prejuicios. 


\section{LÉXICO, LEXICOGRAFÍA E IDENTIDAD}

La inclusión de elementos léxicos procedentes de varios idiomas judíos en un solo léxico debe interesarnos aquí porque su existencia evidencia y simboliza la fragmentación fundamental del pueblo judío. Antes de indagar los significados de esta elección, es necesario reflexionar sobre el rol y poder simbólico del diccionario como elemento emblemático representante de un pueblo o conjunto de pueblos. Según Philip Seargeant, un diccionario, especialmente un diccionario de una variedad específica de una lengua (como en el análisis de Seargeant, los de los "world Englishes" (Seargeant 2011)), se basa en y difunde ciertas ideas sobre la relación entre sociedad e idioma: "[t]he practice is thus based on two premises about language and its relationship to society: (1) a belief in the existence of discrete languages, and (2) a belief in the essential bond between a nation's population and its linguistic practices" (2011: 6). Aunque, como hemos discutido, Gal e Irvine indican lo problemático de estas suposiciones, siguen vigentes en las prácticas de composición y utilización de diccionarios nacionales. Seargeant aclara que " $[\mathrm{t}]$ he belief at work here is that individual nations have distinct systems of language use, and that codifying this in a 'national' dictionary symbolises an independent cultural identity" (2011:6). Así, el diccionario juega un rol legitimador codificando en un "authorative record" (Seargeant 2011:2) el idioma de un pueblo. El nuevo Diccionario de mexicanismos (de ahora en adelante DM) se apoya en estas mismas ideas. En las palabras introductorias de un artículo sobre su obra lexicográfica, Concepción Company explica:

una manera inequívoca de conocer el conjunto de rasgos propios de una colectividad, su identidad, es observar cómo se expresa y mediante qué rutinas o hábitos lingüísticos lo hace o la ha venido haciendo por siglos. La lengua es el sistema que mejor permite acercarse, si bien nunca de manera directa, a la organización conceptual y la visión del mundo del ser humano (2011: 50).

Pues, el DM se aprovecha de este concepto de que el lenguaje revela la identidad de un grupo. Y esta relación, así como el carácter delimitado de las entidades relacionadas -lengua e identidad-, resulta también naturalizada ${ }^{7}$. Como señala J. Gutiérrez Cuadrado, dado que un diccionario:

7 Como explica Del Valle, el diccionario de Company y su manera de presentarlo generó cierta polémica entre la autora y Lara en la que este último culpa a Company de no presentar 
se ofrece él mismo como representante de la lengua en la que los miembros de una sociedad han crecido, han descubierto el mundo y se reconocen, es normal que, en principio, el usuario se vea abocado a aceptar el texto que encierra el diccionario como algo natural (2011: 40).

Un diccionario es el espacio donde se valida, oficializa e institucionaliza la lengua y el usuario toma como inherente e incuestionable su autoridad y la autenticidad de sus lemas. Phil Benson afirma que, incluso para "most modern lexicographers, lexicography is a process of description and the rules and principles of lexicographical practice constrain the lexicographer to 'accuracy' and 'objectivity"' (2001:9). Con la autoridad de la objetividad, un diccionario puede imponer unidad prescribiendo las normas y dando la impresión de homogeneidad al declararse el representante oficial del uso del lenguaje. Como señala Seargeant, esto es propio del diccionario monolingüe: "[j]]ust as a named language is understood to be monolithic (e.g., the English language), so, through a process of logical elision, any dictionary which records this language is understood as the unitary record of the language" (2011: 2).

A pesar de lo problemático de las bases en que se fundan estas ideas, es por eso que se les presta tanta atención al poder y la influencia del diccionario de la Real Academia Española. En su introducción al libro Ideolex, F. San Vicente, C. Garriga y H. E. Lombardini hablan del dominio del DRAE. Dicen que "ha constituido una pieza clave en la codificación (a veces, imposición) de la unificación lingüística, cultural y, por lo tanto, ideológica de diferentes naciones y territorios de habla española" (2011: 10). Por más de dos siglos, lingüistas de distintos países han visto esta hegemonía lingüística con cierta sospecha (Del Valle y Gabriel-Stheeman 2004, Senz y Alberte 2011). El mismo hecho de recopilar y utilizar un diccionario propio puede convertirse en acto nacionalista porque „una obra lexicográfica, sobre todo la monolingüe general, sirve para legitimar, junto a otras obras didácticas, una lengua en un determinado contexto geopolítico" (San Vicente et al. 2011: 12). La publicación de un diccionario, por tanto, puede representar un gesto oficial para diferenciarse de otras naciones. Ya tan solo por su mera existencia es el representante de un pueblo único o de varios pueblos inseparablemente

un léxico puramente nacional sino de crear una obra que reproduce el mismo paradigma colonial que presenta a México como periférico en contraste con el centro español. La acusa de no solo olvidarse de otros diccionarios nacionales latinoamericanos (o sea, los integrales del español de México y Argentina), sino también de utilizar el español de España como único punto de comparación (Del Valle 2014: 105-107). De todos modos, todavía se ve en el DM un deseo de vincular y de aprovechar el vínculo lengua-identidad en un diccionario. 
relacionados. Y además declara la unidad de estos hablantes al reunir su léxico -el símbolo e instrumento de su expresión identitaria-y la mantiene mediante el refuerzo de su poder normativo.

El Léxico Judío Latinoamericano (de ahora en adelante $L J L$ ) sugiere que los judíos latinoamericanos constituyen un grupo homogéneo con derecho a nombrarse y legitimarse a través de la exposición y codificación de un léxico propio. Se propone a los judíos, ya desde el nombre que se le da al texto, como un subgrupo particular dentro de un colectivo más general que es o debería ser el de los latinoamericanos hispanohablantes. Así, el $L J L$ afirma la presencia de un grupo con rasgos propios dentro del idioma español y, por eso, dentro de una cultura dominante (la latinoamericana y lo que con este término se asocie), y sostiene un derecho y deseo a declarar su diferencia y ser reconocido como distinto. En su página de bienvenida, se describe como "una base de datos colaborativa de palabras que usan los judíos hispanohablantes de Latinoamérica y el Caribe, en la escritura y en el habla" ( $L J L)$. A partir de estas ideas totalizantes de lo latinoamericano-aquí designado por su región geográfica-y lo judío, se fragmenta en diferencias. Latinoamérica y la identidad judía aparecen presentadas, de entrada, come entidades homogéneas o monolíticas que constituyen una unidad. Pero, después se procede a matizar la complejidad interna del judaísmo y su historia lingüística. La descripción de la página de acogida sigue:

Las palabras incluidas en esta base de datos se derivan de muchos idiomas hablados por los judíos desde el pasado hasta la época actual. Entre ellos se encuentran el hebreo y el arameo de los textos bíblicos y rabínicos; el judeo-árabe, ladino e ídish de las antiguas tierras ancestrales y el hebreo moderno del Estado de Israel. Asimismo, la base de datos incluye palabras y frases en español que tienen significados únicos entre judíos y cuyo sentido varía cuando se usan entre hablantes judíos o entre hablantes no judíos $(L J L)$.

Aunque el $L J L$ pretende reunir las palabras de cierta población dentro de los países latinoamericanos y caribeños, hace hincapié en que sus vocablos provienen de muchos idiomas diferentes, hecho que, como ya hemos visto, ha simbolizado las fracturas en el pueblo judío. A raíz de esto se nos plantean preguntas tales como: ¿Qué significa el gesto de reunir todas estas lenguas/ historias lingüísticas bajo una misma etiqueta, la de "judío latinoamericano"? ¿Acaso están sugiriendo los editores que el grupo judío debe o puede pensarse unido aún admitiendo estas diferencias lingüísticas? ¿Es el diccionario una señal de que esto ya está pasando o se propone como base desde la cual puede empezar un proceso unificador, un lugar desde donde pensarse cómo "nación" unida? 
Si el deseo es construir un espacio, por lo menos teórico, en el que se pueda pensar a los judíos latinoamericanos como pueblo vagamente unido, el léxico no solo tiene que enfrentarse con diferencias internas de la comunidad judía sino también con diferencias geográficas. Los lemas incluyen una sección de "Quiénes suelen usarla" que reconoce diferencias de ascendencia y de población en general. Se puede señalar que se usa la palabra o frase entre "Ashkenazím" o "Shamis, Halebis" o entre "jóvenes", pero a veces solo se indica que se usa entre "Judíos". Esto último resulta bastante problemático. ¿Sugiere que todos los judíos utilizan esta palabra o solo los judíos del país que nombra el lema? Quizás una palabra como "goy", término proveniente del hebreo y del ídish que denomina una persona no judía, sea conocida por todos los "Judíos"8 pero "halebi", o una "persona de origen alepino; miembro de la Comunidad Maguen David", parece más específico a México donde hay más judíos de Alepo y la comunidad mencionada. A pesar de la confusión de lemas como ésas, normalmente la sección "Países" indica otra especificidad y así otra división interna de la comunidad de este léxico, o sea, la geográfica. Hay palabras y frases de México, Argentina, Venezuela, Brasil, y Uruguay y algunas son de "varios países". Incluir más de un país en esta categoría ya implica conexiones que reducen las fracturas entre judíos de distintos lugares, pero en ciertos lemas el léxico refuerza y complica esta idea comparando usos. Por ejemplo, nota que la palabra "paisano" en Argentina significa "judío" mientras que en México es "judío de la misma comunidad que el hablante". Con su origen en el español, esta palabra es única de los judíos hispanohablantes y vincula judíos latinoamericanos de continentes distintos. Pero, a pesar de sus usos similares, todavía señala una diferencia bastante marcada entre las comunidades mexicanas y argentinas, la de poner o no mucho énfasis en las disparidad entre orígenes. A pesar de la complejidad que admite, este léxico ofrece a los judíos de diferentes ascendencias y lugares una oportunidad para consultar palabras y, en ese acto, construirse y percibir las normas de otras comunidades dentro de una "nación" más amplia.

Los posibles detractores del diccionario podrían tachar los mensajes propuestos de absurdos, precisamente porque la ideología de un diccionario -especialmente uno con pretensiones o implicaciones "nacionales"-depende de la apariencia de homogeneidad. Pero, es posible mantener esta apariencia

8 Mis razones para pensar esto son tan especulativas como las del lema. Es una conjetura basada en el hecho de que proviene del hebreo, el cual ha sido común a todos los judíos históricamente, y porque esta palabra se escucha mucho en la comedia judía estadounidense, la cual tiene una diseminación bastante extendida entre judíos latinoamericanos. 
a pesar de las diferencias internas. Kroskrity habla de la importancia del "foundational emphasis on homogenous language" en las teorías del nacionalismo, pero señala también lo absurdo de mantener esta imagen de las lenguas nacionales, llamando esta práctica "more an uncritical reproduction of folk theories than a considered interpretation of socially distributed linguistic variation" (1999: 24). Observa, además, cierta artificialidad en los intentos de preservar la pureza lingüística entre los "Arizona Tewa" cuya élite ceremonial "used a dominant language ideology as a recourse in the 'erasure' ...of clan and class difference in order to create an 'ethnic' identity as Arizona Tewa Villagers" (15). En su trabajo describe cómo los Tewa realizan este "project of ethnic boundary maintenance", enfatizando las diferencias con el pueblo vecino de los Hopi (25). Así, la discordancia interna se ofusca al subrayar las diferencias externas. Se puede decir que esto es lo que hace el $L J L$ con lemas como "paisano" donde se distingue su significado de su homólogo español. A pesar de reconocer sus divisiones internas, el $L J L$ también pretende circunscribir una población específica por darle fronteras. Los criterios que utiliza el $L J L$ para los judaísmos son': la población que los usa, la región por donde están distribuidos y las diferencias que representan respecto al idioma de otras poblaciones. La descripción de la base de datos incluye palabras y frases españolas que "tienen significados únicos entre judíos y cuyo sentido varía cuando se usan entre hablantes judíos o entre hablantes no judíos", señalando que incluso en situaciones donde aparentan ser idénticas a las usadas por los no judíos todavía hay diferencias fundamentales. Si bien este criterio apunta a la definición del judaísmo, el proceso tiende a elidir la diversidad dentro de lo supuestamente latinoamericano.

El $L J L$ es consciente de que pretende reunir palabras asociadas a grupos judíos distintos e intenta justificar sus motivos. Parte de la razón por la cual incluye tantos orígenes diferentes es también por motivos prácticos; a veces es difícil discernir el origen específico de una palabra. El sitio explica en la sección "Apuntes" que "muchas palabras en ídish, ladino y judeo-árabe se derivan originalmente del hebreo o del arameo textual". Además, parte del desarrollo del ladino tuvo lugar en las mismas regiones geográficas donde se hablaba también judeo-árabe; por eso hubo influencia entre los dos y es difícil decir de qué idioma proviene una palabra aunque exista en ambos. La existencia del árabe en el turco -que influenció el ladino de

9 Con "judaísmos" me refiero aquí, como ya se ha dicho anteriormente, a palabras o frases que provienen de o tienen significados especiales para hablantes judíos. 
los judíos en las zonas del antiguo Imperio otomano- también presenta problemas por no poder asignar con certeza el origen de las palabras. Uno de los aspectos notables del $L J L$ es que reconoce las divisiones internas sin adoptar una actitud purista u homogeneísta ante ellas. Por lo demás, registra diferencias dentro de lo que representa el léxico latinoamericano al incluir en sus definiciones una explicación de "Países" en los que se usa. Incluso crea categorías como "Quién suele usarla" para señalar otras divisiones y coincidencias internas. En el nivel de los lemas específicos, parece que no quiere ofuscar la diversidad interna del idioma y la población que señala. Quiere indagar las complejas dinámicas internas en este léxico polivocal ${ }^{10}$. Pero, a pesar de estas clarificaciones de diferencias de origen y uso, el $L J L$ sigue proponiendo una población unida por un idioma distinto del que la rodea.

\section{UN CONTENIDO DEMOCRÁTICO Y EN CONSTRUCCIÓN}

Más allá de la incorporación de vocablos oriundos de varios idiomas en un léxico, el $L J L$ es susceptible de ser analizado por su contenido y proceso de selección. El Léxico es un proyecto colaborativo y aún incompleto, que por el momento (agosto 2016) tan solo incluye ciento cincuenta y tres lemas. El hecho de que sea un léxico siempre en vías de elaboración dificulta afirmar su carácter representativo y por ello evaluar si refleja su objeto con fidelidad o si comunica prejuicios no declarados en la constitución del contenido. Se puede responder a cualquier queja sobre la falta o presencia excesiva de ciertos términos alegando que el léxico todavía no está completo. Un examen del tipo que hace Gutiérrez Cuadrado en su artículo sobre ideologías y lexicografías, en el cual interpreta los mensajes ideológicos comunicados por la falta o presencia de diferentes palabras y definiciones, es poco útil en este caso. Pero hay una conciencia en el $L J L$ de que las condiciones de su creación han afectado el contenido y explica esta problemática en su página de bienvenida:

10 Distingo "polivocal" de "univocal" en el sentido de que este léxico no es el producto de una única voz editorial ni incorpora el lenguaje de una comunidad indivisa. 
El $L J L$ es un trabajo en progreso; en este momento, la mayoría de las palabras que contiene se usan entre judíos sirios en la Ciudad de México. Nuestra intención es expandirlo para abarcar palabras de otras comunidades judías de México y de otros países.

Es decir que reconoce sus deficiencias y no ignora las circunstancias de su creación que han influido en el perfil del producto que se ofrece hoy. Como hemos dicho, su primera respuesta es subrayar la condición de "trabajo en curso", pero también alertar al usuario de la presencia desproporcionada de palabras asociadas a los judíos sirios. Esto se debe al trabajo de la impulsora del léxico, Evelyn Dean-Olmsted, quien estableció la base del diccionario con sus estudios doctorales plasmados en su tesis, Speaking Shami: Syrian Jewish Language Practices as Strategies of Integration and Legitimation. El sitio web es muy claro sobre esto y lo señala también en su página de bienvenida. Pero, el estado sesgado e incompleto en que se encuentra aún la base de datos plantea otras preguntas sobre la naturaleza y funcionalidad del diccionario. ¿Podemos decir que es un recurso o solo representa una intención? ¿Cuál es esta intención y qué otras intenciones revela implícitamente?

El $L J L$ espera enmendar esta situación recogiendo más contribuciones. En la página de bienvenida pide la ayuda de los usuarios:

Esperamos que tú nos puedas ayudar a construirlo y mejorarlo. Si quieres añadir una palabra que no aparece aquí o modificar alguna definición, por favor haz clic en el botón "Editar" en la fila correspondiente.

La elaboración de un diccionario es un acto que interviene en el orden lingüístico de una comunidad. Un grupo o una institución elabora normas y criterios y decide qué palabras son dignas de ser recogidas y representadas en la obra. Suele existir un ente oficial al que son atribuibles ciertas credenciales y que decide de forma definitiva sobre los usos de un término. La relación entre compositor y usuario es bastante estática y jerárquica: ocupan lugares distintos en los que el primero tiene juicio y conocimiento y el segundo busca o verifica sus conocimientos léxicos. Invitar al usuario a contribuir al volumen rompe esta relación y la reemplaza con un proceso mucho más democrático. Da la impresión de que el consumidor del léxico tiene voz y voto en la composición de algo que, al fin y al cabo, moldea y representa su forma de hablar y por lo mismo su forma de ser. Con el uso de la forma pronominal informal "tú" en esa invitación refuerza la idea de familiaridad y el hecho de que se puedan "editar" y "modificar" los lemas ya existentes le añade el valor de que nadie tiene suficiente autoridad como para tener la última palabra. El $L J L$ pone también a disposición un foro donde los usuarios disponen de más espacio para expresar y discutir sus opiniones. Este modelo 
puede ocasionar la percepción de que este léxico es poco más que una diversión y que le falta la fiabilidad de un documento elaborado de acuerdo con los protocolos de la lexicografía. A veces, las lemas manifiestan una intención de demostrar esa fiabilidad. Incluyen citaciones en sus ejemplos o "fuentes escritas en que aparece la palabra", pero es difícil seguir las pistas de esta información. Al mismo tiempo, se puede interpretar este léxico como señal de un cambio en la naturaleza de la autoridad ocasionado o por la singularidad de esta situación, que es única no solo por el léxico que busca describir sino también por el espacio geográfico en el que esta investigación se desarrolla (o sea, en ciberespacio y a través de toda Latinoamérica), o por la época en la que se realiza este proyecto. Internet cambia por completo la manera de abordar proyectos de colección y documentación. En nuestra era de Wikipedia, donde pareciera que todos pueden contribuir a la constitución del saber, se puede ver un cambio posible en la naturaleza de la autoridad en la descripción de hechos "naturales". Las entradas de Wikipedia funcionan a base de un consenso de usuarios-autores en lugar de expertos informados por investigación original y parámetros de "objetividad" decididos por instituciones a veces percibidas como intocables. Pero, David C. Caverly y Anne Ward tienen cuidado de señalar que "Wikipedia does not purport to present the 'truth' about what is known about a given topic as documented by experts. Rather, it presents what the 'crowd' thinks is the truth using a different epistemological set of standards" (2008: 36). Aunque pone en duda la fiabilidad de los lemas incluidos, el carácter colaborativo y de código abierto del $L J L$ nos mueve a preguntar si acaso refleja mejor a la gente que describe porque supuestamente viene de sus constituyentes.

En el ámbito anglófono, existen diccionarios de judaísmos publicados en forma de libro como el Frumspeak: The First Dictionary of Yeshivish de Chaim Weiser, The JPS Dictionary of Jewish Words de Joyce Eisenberg and Ellen Scolnic, o el Dictionary of Jewish Usage: A Popular Guide to the Use of Jewish Terms de Sol Steinmetz ${ }^{11}$. El LJL con su promesa de participación constante de usuarios-autores representa un cambio no solo al nivel de la autoridad constitucional sino también en la cuestión de la codificación del saber. Juha Suoranta y Tere Vadén hablan de las prácticas internas de Wikipedia y del significado ideológico de la oportunidad de editar entradas:

11 Hoy en día en el mundo angloparlante, diccionarios como estos forman parte de investigaciones que siguen con cuestiones abiertas sobre la definición de lo que es una lengua judía. Para más información sobre eso, se puede ver Bunin Benor, Sarah "Towards a New Understanding of Jewish Language in the Twenty-First Century". Religion Compass 2/6, 2008, 1062-1080. 
"The existence of the 'edit' button already indicates a subtle but profound epistemological shift: knowledge comes with a past and a future; it is not immutable" (2007: 148). Pero el hecho de circular en internet en lugar de en un volumen impreso refuerza el ethos que el léxico parece encarnar: que siempre se pueden añadir más palabras, que todos pueden participar en su construcción y que estas definiciones no permanecen estáticas. De nuevo, la invitación a colaborar rechaza la fijeza de un volumen impreso y da la impresión de que aquí la comunidad habla por sí misma de una manera que desafía la posibilidad de convertir el habla de este pueblo en algo estático o en objeto de estudio.

Sin embargo, la adición o modificación de un lema no se efectúa sin revisión en el $L J L$, lo cual nos indica que el sentido de autoridad final y jerárquica no ha desaparecido por completo. Cuando una autoridad -en lugar del "tú", de los usuarios, del pueblo representado- toma parte en la formación del diccionario, es importante saber cuál es la naturaleza de esta autoridad y qué prejuicios es posible que implique. Justo después de las instrucciones arriba citadas, el sitio advierte que "[t]odos los cambios tendrán que ser aprobados por los administradores". Veamos, pues, quiénes son estos administradores. En la rúbrica "Sobre Nosotros", dice que "[e]1 sitio es mantenido y administrado por Evelyn Dean-Olmsted, Sarah Bunin Benor y Tsvi Sadan". Dean-Olmsted es una antropóloga estadounidense que hizo su doctorado en Indiana University y empezó a enseñar en la Universidad de Puerto Rico en 2013. Como ya señalamos, estudió las comunidades judío-sirias en la Ciudad de México. Sarah Bunin Benor es una profesora del Hebrew Union College en la Loucheim School of Judaic Studies en Los Ángeles; sus ámbitos de especialización son el ídish, el ladino y la identidad judía en el lenguaje. Con un curso que dio en 2007, ella inició el Jewish Lenguaje Research Website en 2002 y el Jewish English Lexicon que también apoya el $L J L$. Tsvi Sadan es un profesor de la Universidad Hebrea de Jerusalén. Es un lingüista nacido en Japón que se mudó a Israel y se especializa, entre otras cosas, en ídish y hebreo.

Desde un punto de vista profesional, estas personas están cualificadas para hablar de estos idiomas y meditar sobre las conexiones entre sus usos y la identidad. Pero ninguno de ellos es latinoamericano ni vive en un país hispanohablante, con la excepción de Dean-Olmsted que acaba de mudarse a Puerto Rico. Por lo tanto, tienen la autoridad institucional suficiente como para determinar la pertinencia de esas palabras para el $L J L$, pero dependen fundamentalmente de los usuarios en relación con las cuestiones de su uso y distribución geográfica, que son las dos categorías desarrolladas en cada definición. Vemos pues que, a pesar de que existe una autoridad con ciertas cualificaciones, regresamos a una igualdad de condiciones en determinadas 
cuestiones de conocimiento. Hay un límite al conocimiento del equipo editorial, y se depende de los usuarios (cuyos contextos no se dan en el sitio web) para contribuir y averiguar información sobre el uso y contexto latinoamericano. La autoridad de esta información se basa en un proceso que aparenta ser democrático: la vigilancia e interés de los usuarios.

Además, los orígenes de las personas que están a cargo del mantenimiento y administración del sitio web merecen ser interrogados porque al fin y al cabo esas personas se erigen en guardianes de este léxico. Con excepción de Sadan, el equipo editorial es estadounidense. Tampoco el apoyo financiero del léxico procede de ningún país latinoamericano porque, al igual que su homólogo inglés, el $L J L$ es auspiciado por la American Academy for Jewish Research Special Initiatives Fund y la Dorot Foundation -las dos basadas en los Estados Unidos. Aunque podemos decir que el $L J L$ emplea un proceso democrático en la elaboración de su contenido, la selección se lleva a cabo desde los Estados Unidos. Este hecho es bastante sugerente porque significa que este país, no latinoamericano, desempeña un rol importante en la representación y estandarización de la cultura de los judíos de otras partes del mundo. Eso se evidencia en el nombre del proyecto; que puede recibir solo desde afuera la monolítica y totalizante etiqueta de "latinoamericano". En Latin Americanism, Román de la Campa (1999) examina la construcción de latinoamericanismo como objeto del campo intelectual y comercial en la academia y el mercado estadounidense mientras que Walter Mignolo en The Idea of Latin America (2005) explica la idea de Latinoamérica como producto del colonialismo/modernidad donde (desde la Guerra Fría) el nuevo imperio que mantiene esta construcción es Estados Unidos. Existen otros ejemplos de la comunidad judía estadounidense que han intentando fomentar y organizar identidades y congregaciones judías en países foráneos. Existen incluso viajes organizados para grupos de visita a Cuba para proporcionar soporte económico. El hecho de que personas de afuera desempeñen un papel tan importante en crear un léxico latinoamericano nos debe hacer reflexionar no solo acerca del influjo que pueden ejercer en la autodefinición de los judíos que representan, sino también porque esto puede objetivar su idioma en lugar de reanimarlo. En un estudio hecho sobre el Vocabulario rioplatense razonado (1889), Daniela Lauria (2010b) habla de las metas y consecuencias del léxico de indigenismos hecho por el español Daniel Granada. Granada era foráneo al grupo que pretendía estudiar y sus objetivos al reunir este léxico tenían que ver con su utilidad para el establecimiento de la nación argentina. A pesar de su apoyo y respecto de la población e idioma que documenta, Lauria admite que "el componente léxico de las lenguas nativas americanas se aborda como objeto de estudio, esto es, como lengua objeto (se habla sobre esas lenguas pero no desde esas mismas lenguas)" (2010b: 
186). Dejan de ser cosas vivas, símbolos de un mundo viviente y -en parte por el hecho de que pertenecen a una población que el país estaba en proceso de exterminar- pasan "a ser tratados como piezas de museo (reliquias) que se debían reunir, coleccionar y conservar" (2010b: 185). Representan un archivo creado para memorializar algo muerto y no para guiar algo vivo. Regresamos, por lo tanto, de nuevo a la pregunta de qué pretende hacer este léxico en realidad. ¿Producir una guía para el uso continuo de una lengua o registro floreciente o coleccionar las curiosidades de una cultura ajena? ¿Manifestar ansiedad ante la desaparición inminente de esos idiomas que vinculan a los judíos estadounidenses con los latinoamericanos?

\section{DESPLAZAMIENTO FUNCIONAL DEL DICCIONARIO}

Normalmente, un diccionario suele tener una función pedagógica: los usuarios lo consultan para aprender o comprobar los usos normativos de ciertas palabras o frases. Sin embargo, el propósito que impulsa la creación del $L J L$ no parece ser la estandarización del empleo de estas palabras. Más bien el $L J L$ parece agruparlas solo para tenerlas reunidas, para probar y documentar su existencia, para visibilizar algo poco visto. Así, el léxico se convierte en un tipo de archivo, juntando pedazos léxicos de un pueblo para decirles quiénes son y cuál es su herencia. Como ya hemos discutido, un diccionario puede tener un objetivo similar al del archivo porque valida la existencia objetiva de un pueblo codificando su lenguaje al tiempo que fomenta un sentimiento de comunidad y solidaridad proponiendo un idioma único y compartido. Además, es posible pensar el diccionario como una práctica de archivo como hace José Nunes que resume la función y el poder de las prácticas del archivo de la siguiente manera: "As práticas institucionais e de arquivo realizam um trabalho de interpretação que direciona os sentidos, estabelecendo uma temporalidade e produzindo uma memória estabilizada" (2008: 80). Pero la diferencia fundamental, que me parece importante subrayar aquí, es que un archivo intenta documentar y crear memoria, y formar desde este punto de partida un sentimiento nacional. Colecciona reliquias del pasado y elementos del presente que el día de mañana serán los vestigios del pasado. El ídish, el ladino y el judeo-árabe están desapareciendo como idiomas autónomos y los pocos hablantes que quedan son mayores. Las palabras de estas lenguas que persisten y aparecen en otras mayoritarias son los vestigios de idiomas en proceso de extinción. Entonces, ¿las palabras incluidas y aún por incluir en el $L J L$ forman parte de un archivo-museo o un 
archivo-mausoleo? ¿Este diccionario tiene una motivación pedagógica que vincula el presente al pasado o es un puro producto del temor a la pérdida? El $L J L$, en cierto modo, quiere prevenir la desaparición total de esos idiomas y refleja un deseo similar entre los que todavía incluyen estas palabras en sus expresiones.

Veo, por lo tanto, en este léxico un intento de visibilizar campos lingüísticos de menos interés fuera del ámbito académico y de reforzar la idea de un pueblo judío -aquí judío latinoamericano- unido a pesar de sus diferencias internas. Quiere superar las divisiones del pasado diaspórico y las fronteras estatales y reforzar la idea de una nación judía cuyos miembros están más unidos y son más homogéneos que nunca. Pero, su manera de hacerlo es problemática; proviene de y propone una visión sumamente estadounidense. No solo proyecta una mirada hacia Latinoamérica que la toma como geografía monolítica, sino también resulta de preocupaciones que reciben más atención en los Estados Unidos. Entre las instituciones judías estadounidenses prevalece el deseo de crear un sentimiento de "nación" o "pueblo" judío. Hay algunos que dicen que la solidaridad judía internacional ha desaparecido después de los $80^{12}$. En los últimos años se han organizado conferencias que se centran en el estado y educación del "Jewish Peoplehood" entre jóvenes y adultos judíos ${ }^{13}$. El proyecto de reforzar una identidad comunitaria judía positiva -que no solo se base en una historia de persecución- ha aumentado en importancia en las últimas décadas en los Estados Unidos. Dadas esas preocupaciones, veo en el $L J L$, si no un intento, por lo menos una herramienta para fomentar un sentimiento ligado a la existencia de un pueblo judío mundial. El $L J L$ transmite la impresión de que todos los judíos comparten un pasado lingüístico en los vocablos procedentes de diferentes idiomas que reúne bajo una misma etiqueta de "palabras judías". Las palabras incluidas en este léxico se convierten en un pasado mutuo porque se vinculan a un pasado diaspórico que siempre ha formado parte del tejido de la historia judía y porque, actualmente, todos conocen la amenaza de la pérdida total de estos hilos lingüísticos. Aunque no se usan esos idiomas como se empleaban en el pasado, el léxico -y la forma particular en que se compone- puede representar un nuevo capítulo en la idea del pueblo judío, un pueblo unido que decide cómo preservar su

12 Jack Wertheimer habla del cambio en las actitudes de la judería mundial después de lo que sufrieron los judíos soviéticos a finales de los ochenta en (2006).

13 Se pueden leer las actas publicadas de la conferencia patrocinada por el Department for Jewish Zionist Education, Jewish Agency for Israel, y el UJA-Federation of New York en Menachem Revivi y Ezra Kopelowitz (eds.). 2008. 
pasado y su presente, un pueblo unido que determina el lugar de este pasado en su presente y su futuro, un pueblo unido que arma su léxico tal como existe y ha existido.

\section{REFERENCIAS BIBLIOGRÁFICAS}

Agosín, Marjorie. 2005. Memory, Oblivion and Jewish Literature in Latin America. Austin, TX: University of Texas Press.

Benson, Phil. 2001. Ethnocentrism and the English Dictionary. Routledge.

Bunin Benor, SARAH. 2008. Towards a New Understanding of Jewish Language in the TwentyFirst Century. Religion Compass 2 (6): 1062-1080.

Caverly, David C. y Anne Ward. Invierno 2008. Techtalk: Wikis and Collaborative Knowledge Construction. Journal of Developmental Education 32 (2): 36-37.

Company Company, Concepción. 2011. Un diccionario a debate. Letras Libres. Abril: 50-56.

DeAn-Olmsted, Evelyn. 2012. Speaking Shami: Syrian Jewish Mexican Language Practices as Strategies of Integration and Legitimation. Tesis doctoral. Bloomington, IN: Department of Anthropology, Indiana University.

DE LA CAMPA, RomÁn. 1999. Latin Americanism. Minneapolis; London: University of Minnesota Press.

DEL VALLE, José. 2007. Glotopolítica, ideología y discurso: categorías para el estudio del estatus simbólico del español. La lengua, ¿patria común? En José del Valle (ed.), pp. 13-30.

2014. Lo político del lenguaje y los límites de la política lingüística panhispánica. Boletín de Filología XLIX (2): 87-112.

DEL VALLe, José (ed.). 2007. La lengua, ¿patria común? Madrid y Fráncfort: Iberoamericana $/$ Vervuert.

del Valle, José y Luis Gabriel-Stheeman (eds.). 2004. La batalla del idioma. La intelecutalidad hispánica ante la lengua. Madrid y Fráncfort: Iberoamericana / Vervuert.

Forgas BERDEt, Esther. 2001. Diccionario e ideología: tres décadas de la sociedad española a través de los ejemplos lexicográficos. Espéculo. Revista de estudios literarios [en línea]. Disponible en http://www.ucm.es/info/especulo/numero17/3decadas.html [Consulta 29/6/2016].

1996. Lengua, sociedad y diccionario: La ideología. En Esther Forgas Berdet (ed.), pp. 71-90.

Forgas Berdet, Esther (ed.). 1996. Léxico y diccionario. Tarragona: Departament de Filogies Romàniques, Universitat Rovira i Virgili.

GaL, Susan y Judith IRvine. Invierno 1995. The Boundaries of Language and Disciplines: How Ideologies Construct Difference. Social Research 62.4. Defining the Boundaries of Social Inquiry: 967-1001.

GutiérRRez CuAdRADo, J. 2011. Ideología y lexicografía: El discurso del diccionario, espejo y trampantojo de la sociedad. En Félix San Vicente, Cecilio Garriga y Hugo E. Lombardini (eds.), pp. 25-66.

Joseph, John E. 2004. Language and Identity: National, Ethnic, Religious. New York: Palgrave Macmillan.

Kopelowitz, Ezra y Menachem Revivi (eds.). 2008. Jewish Peoplehood: Change and Challenge. Brighton, MA: Academic Studies Press. 
Kroskrity, Paul. 1999. Regimenting Languages: Language Ideological Perspectives. En Paul Kroskrity (ed.), pp. 1-34.

(ed.). 1999. Regimes of Language: Ideologies, Polities and Identities. Santa Fe, NM: School of American Research Press.

Lara, Luis Fernando. 1996. Teoría del diccionario monolingüe. El Colegio de México.

Lauria, Daniela. 2010a. Lengua y nación en la lexicografía argentina de fines del siglo XIX y principios del XX: Análisis de los mecanismos de ejemplificación y citación. Res Diachronicae 8: 47-70.

2010b. Tratamiento de indigenismos en el Vocabulario rioplatense razonado de Daniel Granada (1889). lanua. Revista Philológica Romanica 10: 175-202.

Léxico Judío-Latinoamericano. 2013. American Academy for Jewish Research Special Initiatives Fund y el Dorot Foundation. [en línea]. Disponible en http:// http://www. jewish-languages.org/lexico-judio-latinoamericano/ [Consulta 30/6/2016].

Mignolo, Walter D. 2005. The Idea of Latin America. Malden; Oxford; Victoria: Blackwell Publishing.

MyнiLl, John. 2004. Language in Jewish Society: Towards a New Understanding. Clevedon, England; Buffalo, NY: Multilingual Matters.

2006. Language, Religion and National Identity in Europe and the Middle East: A Historical Study. Amsterdam/Philadelphia: John Benjamins Publishing Company.

Muñiz Huberman, Angelina. 2005. The Sephardic Legacy. En Marjorie Agosín (ed.), pp. 14-29.

Nissán, Rosa. 1992. Novia que te vea. México: Editiorial Planeta Mexicana.

NunEs, JosÉ HoRTA. 2008. O discurso documental na história de as idéias lingüísticas e o caso dos dicionários. Alfa 52: 81-100.

Rodríguez Barcia, Susana. 2008. La realidad reflativa: Evolución ideológica en el trabajo lexicográfico de la Real Academia Española (1726-2006). Vigo (España): Servizo de Publicacións da Universidade de Vigo.

San Vicente, F., C. Garriga, y H. E. Lombardini (eds.). 2011. Aproximación metodológica al estudio de la ideología en los diccionarios, pp. 9-24. Milán: Polimetrica.

San Vicente, F., C. Garriga, y H. E. Lombardini (eds.). 2011. Ideolex. Estudios de lexicografía e ideología. Milán: Polimetrica.

Schieffelin, Mabi B., Kathryn A. Woolard, y Paul V. Kroskrity (eds.). 1998. Language Ideologies: Practice and Theory. New York: Oxford University Press.

Seargeant, Philip. 2011. Lexicography as a Philosophy of Language. Languages Sciences 33: 1-10.

Senz, Silvia y Montse Alberte (eds.). 2011. El dardo en la academia: Esencia y vigencia de las academias de la lengua. Barcelona: Melusina.

Spolsky, Bernard. 2014. The Languages of the Jews: A Sociolinguistic History. Cambridge: Cambridge University Press.

Suoranta, Juha y Tere Vadén. 2007. From Social to Socialist Media: The Critical Potential of the Wikiworld. Counterpoints 299: 143-162.

Wertheimer, Jack. 1 junio 2006. Whatever Happened to the Jewish People?. Commentary. Commentary Magazine [en línea]. Disponible en http://www.commentarymagazine.com/ article/whatever-happened-to-the-jewish-people/ [Consulta 25/6/2014].

WoOLARD, KATHRYN A. 1998. Introduction: Language ideology as a field of inquiry. En Mabi B. Schieffelin, Kathryn A. Woolard, y Paul V. Kroskrity (eds.), pp. 3-47. 